\title{
Actores de la educación para el desarrollo en la universidad según la Ayuda Oficial al Desarrollo. Espacios para la coordinación *
}

Ma LUZ ORTEGA

Departamento de Economía Aplicada, UNIVERSIDAD LOYOLA ANDALUCÍA, ESPAÑA. E-mail: mlortega@etea.com

Ma ROSA CORDÓN

Fundación ETEA, UNIVERSIDAD LOYOLA ANDALUCÍA, ESPAÑA. E-mail: rosa.cordon@fundacionetea.org

\section{ANTONIO SIANES}

Fundación ETEA, UNIVERSIDAD LOYOLA ANDALUCÍA, ESPAÑA. E-mail: antonio.sianes@fundacionetea.org

\section{RESUMEN}

La crisis económica está afectando gravemente a la financiación del sistema de cooperación en España, y sin duda esto repercutirá en la financiación de la Educación para el Desarrollo realizada en el ámbito universitario. En el presente artículo se hace una descripción de la Ayuda Oficial al Desarrollo española dedicada a Educación para el Desarrollo durante el periodo 2006-2010 en el espacio universitario. El objetivo es mostrar la relevancia que ha tenido este tipo de AOD en dicho espacio durante este periodo; y revelar la especialización y complementariedad en el tipo de actividades que realizan los diferentes actores de la ED en la universidad, lo cual puede suponer una oportunidad para mejorar la eficacia de la ED máxime en un contexto de limitación presupuestaria.

Palabras clave: Ayuda Oficial al Desarrollo, Educación para el Desarrollo, ONGD, universidad.

\section{Agents in Development Education at the University by the Official Development Assistance. An opportunity for coordination}

\begin{abstract}
The current situation of the Spanish cooperation system brings a series of funding cuts that may affect the Development Education at the University. This paper is a description of the Official Development Assistance in Development Education executed during the period 2006-2010 at the University. The aim is to show an overview of it, focusing on the specialization in activities developed by NGOs and the university. This is an opportunity to promote coordination between the two, in order to overcome the expected budgetary limitations.

Keywords: Official Development Assistance, Development Education, NGDO, University.

Clasificación JEL: A22, F35, I20

\footnotetext{
* Esta publicación recoge parte de la investigación 11-PR1-0451 realizada por el Grupo de Estudios de Desarrollo de la Universidad LOYOLA de Andalucía y la Fundación ETEA. Este proyecto ha sido financiado por la Agencia Española de Cooperación Internacional para el Desarrollo (AECID). El contenido es responsabilidad exclusiva de los autores y no refleja necesariamente la opinión de la AECID. Queremos agradecer especialmente al personal de la antigua DGPOLDE y al Departamento de ONGD de la AECID las bases de datos facilitadas para la realización de este estudio.
}

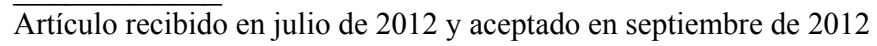

Artículo disponible en versión electrónica en la página www.revista-eea.net, ref. ə-30301 


\section{INTRODUCCIÓN}

En Europa, la Educación para el Desarrollo (ED) ha ido consolidándose cada vez más como un elemento esencial integrante de la Cooperación al Desarrollo y de la Educación Global. Así ha sido reconocido por las distintas instituciones de la Unión Europea a través de la Resolución del Consejo de la Unión Europea (2001), la Declaración de Maastricht 2005-2014 sobre Educación Global en Europa del Centro Norte-Sur del Consejo de Europa (2002) y en el documento El Consenso Europeo sobre el Desarrollo: contribución de la educación y de la sensibilización en materia de desarrollo, elaborado de forma conjunta entre la sociedad civil, el Parlamento Europeo, los Estados Miembros de la Unión Europea y la Comisión Europea, en $2007^{1}$.

En España, la ED también ha vivido en los últimos años una profunda evolución, desde los contenidos y objetivos de la ED, hasta las actividades y espacios en que éstas se ejecutan (Mesa, 2000; Boni, 2005; Ortega 2008).

No en vano, desde que la ED aparece por primera vez en la normativa española en la Ley 23/1998 de Cooperación Internacional al Desarrollo, hasta hoy, han transcurrido poco más de 14 años, y sin embargo ha pasado de ser concebida en dicha ley como un instrumento de la cooperación y definida como un "conjunto de acciones... que favorecen una mejor percepción de la sociedad hacia los problemas que afectan a los países en desarrollo y que estimulan la solidaridad y cooperación activas con los mismos" (Artículo 13), a ser definida como un "proceso educativo constante encaminado... a promover una ciudadanía global generadora de una cultura de la solidaridad comprometida en la lucha contra la pobreza y la exclusión así como con la promoción del desarrollo humano y sostenible" por la Estrategia de Educación para el Desarrollo (Ortega, 2008) y el III Plan Director de la Cooperación Española (MAEC, 2009).

En este proceso de evolución de la ED, el espacio universitario y la presencia en su seno de otros actores como son las Organizaciones No Gubernamentales de de Desarrollo (ONGD), ha sido cada vez mayor (Baselga, et al., 2004). Por su parte, la propia Universidad ${ }^{2}$ se ha ido configurando progresivamente, como un agente financiador (Asenjo et al., 2008) y ejecutor de acciones de ED.

La Universidad a través de las acciones que le son propias: educación, investigación, y demás servicios a la sociedad (Pulido 2007) ${ }^{3}$, se ha instaurado

\footnotetext{
${ }^{1}$ En http://ec.europa.eu/development/icenter/repository/PUBLICATION_CONSENSUS_ES-06700-00.pdf [Último acceso: 28/05/2012]

${ }^{2}$ A lo largo del artículo se utilizará Universidad (en mayúsculas) al hacer referencia a la institución como agente de la AOD, y universidad (en minúsculas) al hacer referencia al espacio o ámbito en el que se desarrollan las actividades de ED.

${ }^{3}$ Emilio Fontela reconoce tres ámbitos a los que la Universidad debe responder: a la educación superior, a la investigación y a una "tercera misión" de servicios diversos a la sociedad. Entre estos
} 
como agente de ED. En numerosas ocasiones, éstas han sido canalizadas a través de una estructura solidaria universitaria, definida como aquélla que "sea cual sea su origen o forma legal u organizativa, tiene como objetivos: el estudio, la promoción, la formación, la investigación, la sensibilización y organización de actividades englobadas dentro de lo que podría denominarse el campo solidario y ejecutadas siempre desde el ámbito universitario" (Arias y Simón, 2004).

La actual coyuntura del sistema de cooperación española, sometido a una profunda reducción de los fondos de la Ayuda Oficial al Desarrollo (AOD) ${ }^{4}$, puede implicar un serio retroceso en la evolución y consolidación de la ED, tanto a nivel general como en el ámbito universitario ${ }^{5}$. Sin embargo, este previsible retroceso en la cantidad de fondos no debería implicar un retroceso en la calidad de las intervenciones, según se desprende de las conclusiones de los foros sobre Armonización (Roma 2003) y Eficacia de la Ayuda (París 2005, Accra 2008, Busán 2011), y las cumbres sobre financiación del desarrollo (Monterrey 2002 y Doha 2008) donde se hicieron sucesivos llamamientos en pos de la eficacia y eficiencia de la ayuda.

En este sentido y ante un panorama de reducción presupuestaria son pertinentes mayores esfuerzos para conseguir una mayor armonización y alineación entre los diferentes actores de la cooperación, pues esto permitirá caminar en la senda de una mayor eficacia y eficiencia en la gestión de unos recursos escasos.

Aplicando estos principios al caso de la ED en el espacio universitario, una mayor armonización y alineación entre los actores pasa por una activa colaboración entre las ONGD, la Universidad y otras instituciones del mundo de la cooperación. Previamente, diversos autores en el campo de la cooperación (Unceta, 2004; Arias y Simón, 2004; Boni, 2006) han señalado la importancia de esta colaboración, que además debe ser "desde la diferencia", para así aprovechar mejor los recursos de los que disponen los distintos agentes (Unceta, 2007). En el presente artículo defendemos que esta afirmación también es aplicable para el caso de la ED realizada en el espacio universitario.

Con esta intención, y a partir del análisis de la AOD española dedicada a Educación para el Desarrollo en el espacio universitario, este trabajo se propone

\footnotetext{
servicios se encuentran aquellos comunes de interés social, otros de interés económico y económicos directamente explotables (para ampliar más sobre este punto consultar en Pulido, 2007).

${ }^{4}$ En 2010 el porcentaje de la AOD con respecto a la Renta Nacional Bruta fue de 0,43\% (MAEC, 2011), mientras que para el año 2012 la partida supondrá un $0,23 \%$, lo implica un paso atrás de 9 años en volumen de ayuda (http://www.abc.es/20120616/espana/abci-cooperacion-internacionalreparto-201206151901.html Último acceso: 21/06/2012).

${ }^{5}$ Una gran parte de los fondos obtenidos por ONGD en el desempeño de las funciones para las que se crearon (entre las que figura la ED) provienen de fondos públicos (Gutiérrez et al. 2009).
} 
dos objetivos: mostrar la relevancia que ha tenido este tipo de AOD en el espacio universitario durante este periodo; y revelar la especialización en el tipo de actividades que realizan los diferentes actores de la ED en la universidad, lo cual puede suponer una oportunidad para mejorar la eficacia de la ED.

El artículo se estructura en tres bloques. En el primero, se detallará el tratamiento de la base de datos oficial de AOD en España para el periodo 20062010, objeto de análisis, a fin de poder utilizar esta fuente de 126.607 registros. En la segunda parte del artículo, se aborda el primer objetivo, analizando la evolución a lo largo del quinquenio de la AOD destinada a ED, en general; y la que se dirige al espacio universitario, en particular. A continuación, para el segundo objetivo, se hace una breve aproximación a las tipologías de actividades de ED existentes y se detalla cuáles, según los datos, se han desarrollado durante el quinquenio para mostrar qué actividades son propias de cada actor ejecutante, y cuáles suponen un espacio de encuentro entre los actores. Finalmente, se presentan las conclusiones más relevantes.

\section{ESTIMACIÓN DE LA AOD EN EDUCACIÓN PARA EL DESARROLLO EN EL ESPACIO UNIVERSITARIO: UNA PROPUESTA METODOLOGÍCA}

En este estudio se han analizado exclusivamente los flujos contabilizados como Ayuda Oficial al Desarrollo (AOD) Bruta Bilateral dedicada a Educación para el Desarrollo en España durante el periodo 2006-2010. Sin embargo, cabe detallar que no todas las acciones de ED, y por ende las realizadas en el espacio universitario ${ }^{6}$, son consideradas en el estudio de la $\mathrm{AOD}^{7}$. No obstante, en la actualidad, el análisis de la AOD sigue siendo la única manera de realizar una aproximación cuantitativa fiable a la ED.

Los datos objeto de este análisis fueron facilitados para esta investigación por la Dirección General de Políticas de Desarrollo (DGPOLDE), actualmente denominada Secretaria General de Cooperación Internacional para el Desarrollo (SGCID). Esta Secretaría General se encarga anualmente de consolidar, filtrar y depurar el conjunto de acciones de la AOD a partir de los datos que le facilitan los diferentes actores públicos. Para ello, sigue los patrones de contabilización establecidos por el Comité de Ayuda al Desarrollo (CAD). Estos datos son pu-

\footnotetext{
${ }^{6}$ El espacio o ámbito universitario hace referencia al público meta al que van destinadas las acciones de ED. Al referirnos a actividades realizadas en el espacio o ámbito universitario nos referimos a la comunidad universitaria y/o a las actividades, que se celebran el espacio físico universitario con independencia de que el público pertenezca o no a dicha comunidad.

${ }^{7}$ Las actividades desarrolladas por el conjunto de actores con fondos privados y no públicos no quedan aquí recogidas, ni tampoco las realizadas con fondos públicos pero que no han sido declaradas como tales. En el caso de la propia Universidad, tal y como se verá en el apartado 4.2, esto ha sido relativamente común.
} 
blicados periódicamente en el documento Plan Anual de Cooperación al Desarrollo Seguimiento (PACI - Seguimiento), donde se reflejan tanto los importes presupuestados como los ejecutados del conjunto de proyectos financiados con cargo a la AOD por los actores de la cooperación española.

La base de datos facilitada por la SGCID era una base de datos única con la totalidad de los registros desde 2006-2010, en donde los campos de los registros de los distintos PACI - Seguimiento estaban homogenizados. Una base que contaba con 126.607 registros, cada uno de ellos con 66 campos.

Esta base de datos consolidada ha sido contrastada con otras dos fuentes:

- Con los distintos PACI - Seguimiento, para incorporar, cuando fue preciso, el campo "beneficiario del proyecto".

- Con la base de datos de convenios de Educación para el Desarrollo facilitada por el Departamento de Proyectos de la AECID, para incluir los importes ejecutados de 2006 a 2010.

A continuación, se describe el proceso de depuración de la base de datos:

1. Del total de registros, se seleccionaron los correspondientes a proyectos de Educación para el Desarrollo, identificados por el CAD con el código CRS99820. Dicho código refleja los gastos para la "Promoción de la concienciación sobre el desarrollo" ", que comprende aquellos gastos que se han realizado en el país donante y que pretenden en los destinatarios "la toma de conciencia o el aumento del interés en la cooperación al desarrollo (folletos, conferencias, proyectos especiales de investigación, etc.)" 9 .

2. Seguidamente, se seleccionaron aquellos registros correspondientes a la AOD bruta bilateral, es decir, el conjunto de actividades de cooperación para el desarrollo realizadas por las administraciones públicas de los países donantes con el país receptor, directamente a través de los gobiernos socios u otros actores locales, o indirectamente a través de organizaciones de desarrollo no guber-

\footnotetext{
${ }^{8}$ La Ayuda Oficial al Desarrollo viene clasificada según sectores de destino de la contribución para que cada intervención se relacione unívocamente con un sector. Los sectores vienen descritos por el CAD mediante el sistema "Creditor Reporting System" (CRS) y facilita un listado de CRS y sus características. http://www.oecd.org/document/18/0,3746,en_2649_ 34447 1914325_1_1_1_1,00.html (Último acceso: 11/05/2012)

${ }^{9}$ El código CRS es una variable de la base de datos. Desgraciadamente la clasificación con un único Código CRS supone depreciar actividades que individualmente podrían contabilizarse con el Código de ED, al estar dentro de proyectos generales clasificados en otro sector CRS. Por ejemplo, todos los convenios de ONGD financiados por la AECID y no consignados con el Código 99820 pueden dedicar anualmente a las actividades de sensibilización entre $10.000 \mathrm{y}$ $12.000 €$ anuales (MAEC 2005). Consideramos que el montante total podría suponer un importe muy alto de ED, pero escapa a las posibilidades de esta investigación conocer las acciones y el público al que fueron dirigidas estas actividades.
} 
namentales ${ }^{10}$. El presente estudio no analiza la AOD Multibilateral y Multilateral en Educación para el Desarrollo puesto que su orientación final no responde a una decisión propia del país, por lo tanto, su tratamiento estadístico no ofrecía información relevante para el presente estudio. Es más, por el contrario, su montante podía desvirtuar el análisis ${ }^{11}$.

3. Por su elevado importe, se procedió a revisar la clasificación CRS de los convenios de ONGD de ED financiados por la AECID. Para ello se contó con una base de datos de convenios de Educación para el Desarrollo facilitada por el Departamento de ONGD de la Agencia Española de Cooperación Internacional para el Desarrollo (AECID).

4. Con la intención de aislar aquellos proyectos de ED que entre su público meta incluían a la población universitaria, se procedió a seleccionar a partir de diversas variables aquellos registros que lo incluían expresamente. Puesto que la base de datos consolidada de la SGCID no ofrecía información sobre el colectivo beneficiario, resultó necesario acudir a la información disponible en otras categorías, tales como el título y descriptor de la intervención y acometer en ellas una búsqueda de palabras clave en relación con la Universidad.

Concretamente se seleccionaron aquellos registros en los que en las variables "Agente Financiador", "Título" o "Descripción", aparecían palabras con la raíz "universit" o su alomorfo "universid" 12 .

5. Una vez depurada la base de datos, se procedió a simplificar y homogeneizar los conceptos analizados en los distintos registros ${ }^{13}$.

El análisis de los distintos registros de AOD en ED en el ámbito universitario $\left(\mathrm{AOD}-\mathrm{ED}_{\text {univ }}\right)$ permitió detectar que la estimación de la $\mathrm{AOD}-\mathrm{ED}_{\text {univ }}$ debía ser distinta si las acciones iban dirigidas al público universitario (personal do-

${ }^{10}$ Extraído del glosario de términos y conceptos de la AECID, en http://www.aecid.es/es/servicios/publicaciones/Publicaciones2/Otros/Normativa/glosario99.html. (Último acceso: 05/06/ 2012)

${ }^{11}$ La AOD Multibilateral destinada a ED supuso para el periodo de estudio 10,60 millones de euros; y la Multilateral, 15,18 millones de euros. Si sumamos ambas cifras, se correspondería con el 10\% de la AOD bruta bilateral destinada a ED. Los fondos destinados a ED Multilateral y Multibilateral se corresponden con contribuciones a organismos multilaterales (Presupuesto de las Comunidades Europeas) y a fondos internacionales (Fondo de Ayuda al Desarrollo de la UE, entre otros), que se imputan al código CRS de Educación para el Desarrollo porque el importe de estas contribuciones se distribuye sectorialmente siguiendo criterios establecidos por la UE, pero que no implican necesariamente actividades de ED.

${ }^{12}$ Este proceder a la hora de seleccionar los datos de la AOD ha sido utilizado previamente con éxito en una estimación de la ayuda a la infancia financiada por el UNICEF-España (ver Alonso, et.al. 2012).

${ }^{13}$ Aquellos que refiriéndose al mismo concepto tomaban nombres distintos (en Entidad Ejecutante, Localización, etc.). Así, a modo de ejemplo, la ONGD Asamblea de Cooperación por la Paz se encontró registrada con cuatro nombres diferentes. 
cente, alumnado, PAS) de forma exclusiva a si estas acciones eran dirigidas a un público no exclusivamente universitario.

Este hecho llevó a definir un nueva variable con el fin de ponderar el flujo financiero considerado como AOD-ED $\mathrm{Eniv}_{\text {uv }}$.

Para la cuantificación de la $A O D-E D_{\text {univ }}$, se llevaron a cabo dos tipos de aproximación a la información disponible. Por un lado, una vía directa, cuando la información ofrecida por el objetivo de la intervención o la población beneficiaria permitía inferir que tenía un impacto exclusivo en el colectivo universitario, asignándole el $100 \%$ del importe. Por otro lado, cuando la información disponible no permitía acudir a esta vía directa, se recurrió a métodos indirectos de estimación del impacto sobre el colectivo universitario, estableciendo un conjunto de criterios que se especificarán más adelante. Lo que se ha pretendido con este conjunto de criterios de asignación directa e indirecta es poder asociar de forma sistemática un factor de ponderación específico a cada intervención analizada. Dicho factor, multiplicado por el monto total desembolsado en cada caso, permitió obtener el volumen de recursos que de esa intervención pueden ser computados.

De los 818 proyectos de AOD-ED ${ }_{\text {univ }}, 181$ eran "no exclusivos" del ámbito universitario. Esto suponía el $45.98 \%$ de lo cuantificado en una primera aproximación ${ }^{14}$. Del importe total de AOD que suponían los proyectos no exclusivos, aproximadamente la mitad $(41,7 \%)$ se correspondía con Convenios de ED firmados entre la AECID y ONGD. Para que este elevado importe no desvirtuara el análisis de la ED destinada "exclusivamente" al ámbito universitario, se procedió a ajustar la cuantía de estos registros. Para lo cual, se contactó con todas las organizaciones beneficiarias de este tipo de convenios durante el periodo 2006-2010, solicitándoles que estimaran el porcentaje de AOD destinado realmente a ED en el espacio universitario ${ }^{15}$.

Para el método de asignación indirecta se procedió a establecer cuatro rangos de ponderación $(0-25 ; 25-50 ; 50-75$ y 75-100) y mediante un panel experto con

\footnotetext{
${ }^{14}$ No en vano varios de estos proyectos intervienen en numerosos espacios, haciendo referencia a

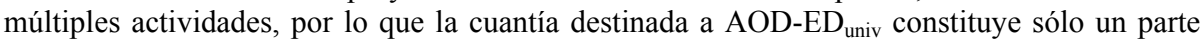
menor de todo el montante del presupuesto. Además, aquí estaban incluidos también los convenios firmados por la AECID con diversas ONGD y que suponían una elevada cuantía, sin ser exclusivos del espacio universitario.

${ }^{15}$ Se contactó con las responsables de todos los convenios de ED analizados: Ayuda en Acción, Intered, Entreculturas, Intermon Oxfam, Instituto de Promoción y Ayuda al Desarrollo, Plataforma 2015, Instituto de Estudios Políticos para América Latina y África e Ingeniería Sin Fronteras, actualmente ONGAWA.
} 
técnicos de ONGD ${ }^{16}$ se establecieron dos clasificaciones y sus respectivos pesos (Tabla 1).

Tabla 1

Porcentajes de ajuste en los proyectos de ED "no exclusivos" del ámbito universitario

\begin{tabular}{|c|c|c|}
\hline & Criterio & $\begin{array}{l}\% \text { de la AOD } \\
\text { desembolsada }\end{array}$ \\
\hline \multicolumn{2}{|c|}{ Proyectos que hacían alusión a un "público general" en su Título o su Descripción. } & $12,5 \%$ \\
\hline \multirow{3}{*}{$\begin{array}{l}\text { Proyectos que no hacían alusión a } \\
\text { ningún actor específico en su Título } \\
\text { o su Descripción. }\end{array}$} & $\begin{array}{l}\text { Actividades propias de la sensibilización e } \\
\text { incidencia. }\end{array}$ & $12,50 \%$ \\
\hline & Actividades de formación. & $37,50 \%$ \\
\hline & Actividades de investigación. & $62,50 \%$ \\
\hline
\end{tabular}

Fuente: Elaboración propia.

A continuación se detallan los pasos seguidos:

- En los proyectos cuyo Título o Descripción hacen referencia al público general o a otro tipo, además del Universitario se determinó que el factor de ponderación sería $12,5 \%{ }^{17}$.

- En el caso de que el proyecto no hiciera mención alguna al tipo de público, se ponderó la cantidad ejecutada en función del tipo de actividad. De manera que, en aquellos proyectos que hacían referencia a acciones de sensibilización e incidencia, que son menos específicas del ámbito universitario, se estimó que un $12,5 \%$ de la AOD desembolsada se dirigía a dicho público. Mientras que en las actividades de formación e investigación, más específicas del espacio universitario, el porcentaje de AOD que se tomó fue mayor (véase la Tabla 1).

\section{EVOLUCIÓN DE LA AOD DESTINADA A EDUCACIÓN PARA EL DESARROLLO EN UNIVERSIDAD}

\subsection{Evolución de la AOD destinada a ED en general}

En la introducción se argumentaba que la ED ha tenido un profundo desarrollo en la última década. Prueba de ello es que el III Plan de Director de la Cooperación Española 2009-2012 la reconoce como uno de los siete ámbitos

\footnotetext{
${ }^{16}$ Las 13 organizaciones participantes en el panel fueron: Comercio Para el Desarrollo, Medicus Mundi, Mujeres en Zona de Conflicto, Cooperación Internacional, Asamblea de Cooperación por la Paz, Asociación Educativa Barbiana, InteRed, Fundación Ecología y Desarrollo, Paz con Dignidad, Fundación Solidaritat Universidad de Barcelona, Fundación Ecología y Desarrollo, ACSUR-Las Segovias, Centro de Investigación para la Paz y Fundación CIDEAL de Cooperación e Investigación.

${ }^{17} 12,5 \%$ es el punto medio en el rango 0 y 25 , primero de cuatro en que podemos dividir el $100 \%$.
} 
estratégicos de la cooperación, y que en 2008 se avanza con la publicación de la Estrategia de Educación para el Desarrollo de la Cooperación Española, marco definitorio a nivel estatal.

Estos hechos podrían ser interpretados como un aumento de la importancia relativa de la ED dentro de la cooperación para el desarrollo.

Sin embargo, a pesar de que las cifras de la AOD bilateral bruta destinada a ED en términos absolutos han aumentado sustancialmente durante el quinquenio 2006-2010, este crecimiento se explica más por el crecimiento del conjunto de la $\mathrm{AOD}$ en el periodo, que por una política expresa que haya derivado en un aumento de la AOD-ED frente al resto de la AOD. Así, la Figura 1 muestra como el crecimiento relativo de la AOD-ED respecto al total de la AOD ha sido moderado y prácticamente se ha mantenido en el intervalo 2-3\% sobre el total de la AOD. De hecho, el porcentaje de la AOD-ED (259 millones de euros) sobre el total de la AOD (9.105 millones de euros) durante el periodo, supuso un 2,83\%, cifra inferior al mínimo del $3 \%$ de la AOD bilateral bruta acordado en el III Plan Director de la Cooperación Española de 2009 a 2012 (MAEC, 2009, pág.:237).

Figura 1

Evolución de la AOD-ED para el periodo 2006-2010

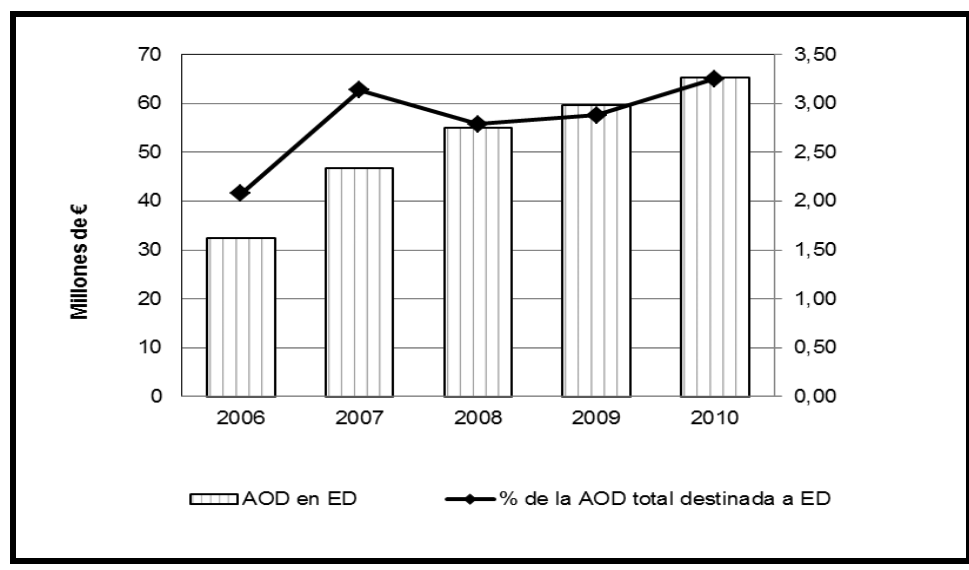

Fuente: Seguimiento PACI consolidado de SGCID (2006-2010). Elaboración propia.

Por lo tanto, en términos cuantitativos, consideramos que el incremento de la ED dentro del sistema de cooperación ha sido moderado en comparación al crecimiento de la AOD, y estas cifras difícilmente permitirán alcanzar al final del periodo lo recogido en el III Plan Director. 


\subsection{Evolución de la AOD destinada a ED en el espacio universitario}

Aunque no existen estudios cuantitativos previos sobre la ED realizada en el espacio universitario según los distintos actores que trabajan en dicho ámbito, sí existen informes que, de manera parcial, reflejan aspectos de esta realidad. Así, un estudio sobre la ED realizada por la Coordinadora de ONGD andaluza (CONGDA) para el periodo 2006-2008 señala que sólo una novena parte de las actividades de ED realizadas por las organizaciones en Andalucía fueron destinadas al público universitario (Macarro y Burgos, 2009). Y en el ámbito de la cooperación universitaria, distintos Seguimientos-PACI (2007 y 2010) sitúan la cuantía de la AOD universitaria destinada a ED en un intervalo que va desde el 14\% (Asenjo, et al. 2008) hasta el 35\% (MAEC, 2011).

No obstante, según los datos analizados en el presente estudio, la AOD-ED ejecutada en el espacio universitario (en adelante $A O D-E_{\text {univ }}$ ) supuso para todo el quinquenio un montante todavía más reducido, de apenas un $6,46 \%$ (16,74 millones de euros) de toda la AOD-ED, lo que representa un $0,18 \%$ de la AOD bruta bilateral.

Todo esto apunta a que, a pesar de existir diversos agentes financiadores y ejecutores de AOD-ED $D_{\text {univ }}$, ésta sigue suponiendo un bajo porcentaje de la AOD, sustanciosamente menor que el estimado por la literatura referida.

En cuanto a la evolución a lo largo del periodo de estudio de la cuantía de $\mathrm{AOD}-\mathrm{ED}_{\text {univ }}$, es necesario hacer una observación previa respecto al proceso de contabilización de la AOD.

El proceso de contabilización de la AOD se hace a partir de la información proporcionada por los organismos oficiales, incluidos las universidades, gobiernos estatales, locales o sus organismos ejecutivos. Las universidades se han incorporado recientemente a este proceso de contabilización (año 2006). Entre ellas, al principio hubo un cierto desconocimiento acerca de qué partidas imputar como AOD, por lo que registraron gastos que posteriormente dejaron de contabilizar, o fueron incorporando nuevos que previamente no habían contemplado. Con el paso del tiempo, entre las universidades se fue creando una cultura de rendición de cuentas y se fueron definiendo criterios comunes sobre la AOD a declarar ${ }^{18}$.

Esta incorporación más tardía de la Universidad al sistema de contabilización de la AOD ha tenido un impacto importante en la evolución de la AOD$\mathrm{ED}_{\text {univ }}$ declarada, pues al ser una cuantía relativamente baja, es sensible a lo que los distintos agentes financiadores, y en concreto la Universidad, declaren como AOD. ${ }^{18}$ Información proporcionada en entrevista telefónica el día 28/06/2012 por la Secretaria Técnica
del OCUD, Dña. Nuria Castejón Silvo. 
Por esta razón, el patrón evolutivo de la $\mathrm{AOD}-\mathrm{ED}_{\text {univ }}$ durante el periodo de estudio, ha sido más errático que el visto para la AOD-ED, con un crecimiento desproporcionado en el año 2007 (véase la Figura 2).

Figura 2

Evolución de la AOD-ED univ para el periodo 2006-2010

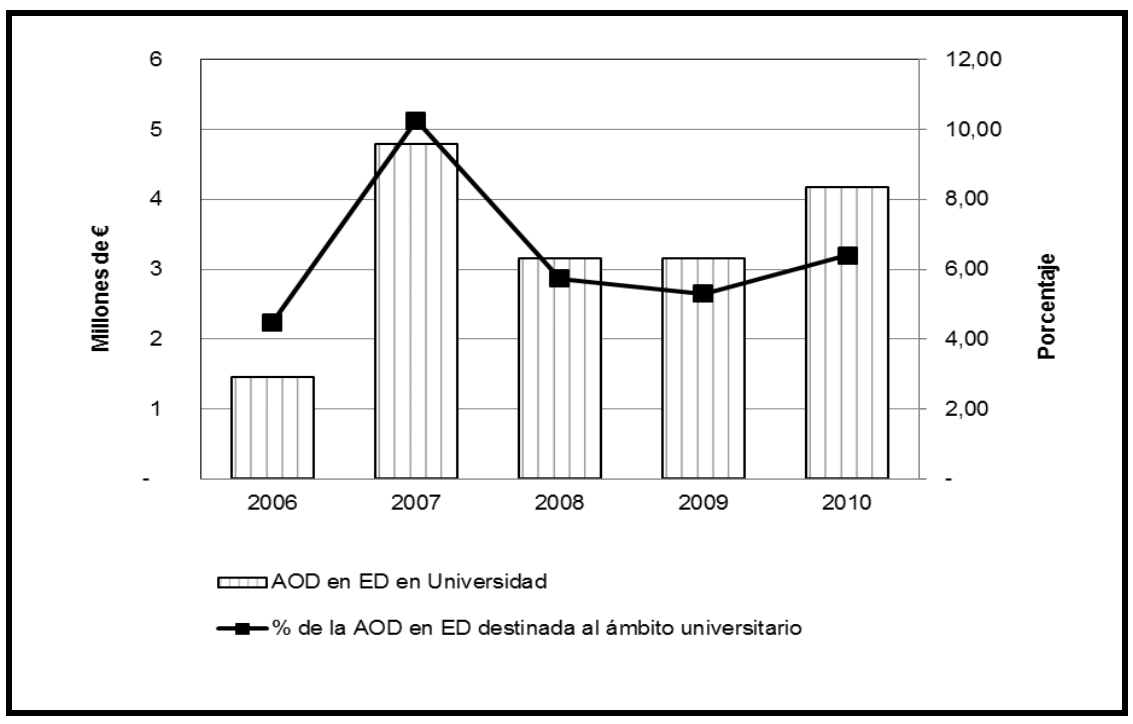

Fuente: Seguimiento PACI consolidado de SGCID (2006-2010). Elaboración propia.

Este crecimiento en las cifras declaradas como AOD-ED $D_{\text {univ }}$ en 2007 , se debió principalmente a la existencia de dos proyectos financiados por la Universidad con montos que exceden el umbral máximo de las cuantías expuestas ese año ${ }^{19}$ y que, según información propia de una de las universidades, fue debido a una falta de claridad inicial acerca de qué declarar como $\mathrm{AOD}^{20}$. Si se substraen esos dos montos, el patrón evolutivo de la AOD tiene un crecimiento más moderado ese año, como puede observarse anotado como $\mathrm{AOD}-\mathrm{ED}_{\text {univ (corregida) }}$ en la Figura 3.

${ }^{19}$ Los montos de financiación de dos proyectos de ED mostraron ser outlier para el año 2007, pues supusieron más de cuatro veces la desviación típica del monto promedio de proyectos en dicho año. Dichos proyectos fueron, uno de la Universidad Politécnica de Valencia relativo a "Asignaturas de cooperación para el desarrollo", que declaró un monto de 736.000 euros, y el proyecto de la Universidad Complutense de Madrid de "Convocatoria a proyectos de cooperación", que declaró 435.343 euros.

${ }^{20}$ Información proporcionada en una entrevista telefónica el día 15/06/2012 por personal del Área de Cooperación al Desarrollo de la UPV. 
Figura 3

Evolución de la AOD-ED univ y AOD-ED univ (corregida) para el periodo 2006-2010

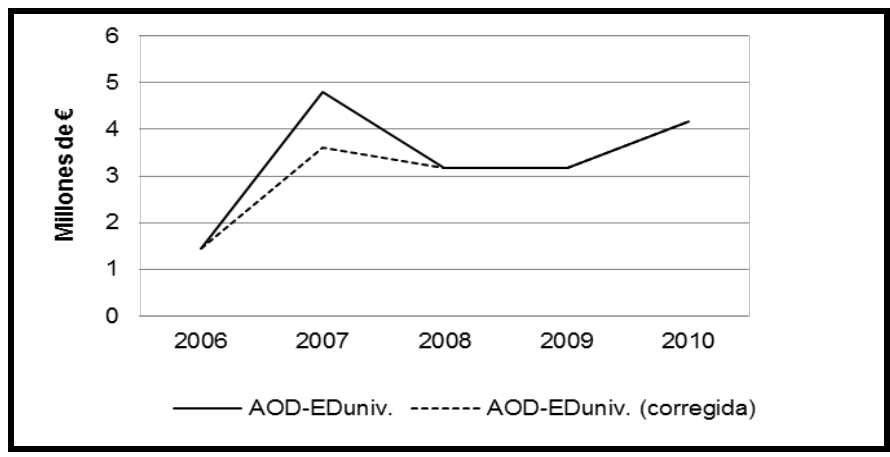

Fuente: Seguimiento PACI consolidado de SGCID (2006-2010). Elaboración propia.

A partir del 2008, con la creación del Observatorio de Cooperación Universitaria para el Desarrollo (OCUD) ${ }^{21}$, se hizo un seguimiento más pormenorizado de lo que las universidades declaraban como $\mathrm{AOD}^{22}$, lo cual tiene reflejo en el patrón de crecimiento más equilibrado de la $\mathrm{AOD}-\mathrm{ED}_{\text {univ }}$ a partir de dicho año (Figura 4).

Teniendo en cuenta esta salvedad, se observa que a lo largo del periodo de

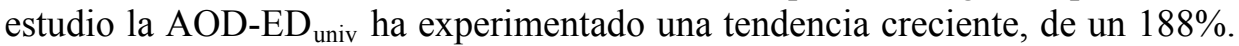
Dicho crecimiento parece sugerir un incremento con el paso del tiempo de la importancia de la ED en el espacio universitario. Empero, un análisis detallado de los datos, muestra que la incorporación de más universidades en el proceso de rendición de cuentas puede haber influido significativamente. Así, y según los datos estudiados, en 2010 el doble de universidades (26) reportaron sus datos de AOD respecto a las del 2006 (13).

\section{ACTIVIDADES DE EDUCACIÓN PARA EL DESARROLLO EN EL ESPACIO UNIVERSITARIO}

A continuación se describe la tipología de actividades de ED contabilizadas como AOD durante el periodo de estudio, debemos recordar aquí que no se trata

${ }^{21}$ Entre sus objetivos incluyó el de facilitar la recopilación de información computable como AOD entre las universidades (Tristán, 2010), lo que contribuyó a la homogeneización y mejora en la rendición de cuentas.

${ }^{22}$ El OCUD en el año 2011, tras un proceso participativo, publicó el documento "Consenso sobre el reporte de la AOD de las universidades: Vigilancia en la calidad de datos y consenso de criterios para la encuesta del PACI de las universidades" (OCUD, 2011) que ya define unos criterios comunes de lo que las universidades deben computar como AOD. 
de toda la ED realizada en el espacio universitario, sino sólo aquella que es contabilizada como Ayuda Oficial para el Desarrollo. Posteriormente, se detallan cuáles han sido realizadas de manera prioritaria por cada actor ejecutante (ONGD y Universidad), y cuáles suponen un espacio de encuentro entre los actores.

\subsection{Hacia una tipología de actividades de Educación para el Desarrollo en el espacio universitario}

La Estrategia de Educación para el Desarrollo de la Cooperación Española (Ortega, 2008) y el III Plan Director de la Cooperación Española 2009-2012 (MAEC, 2009) recogen cuatro dimensiones de la Educación para el Desarrollo, que subyacen, implícita o explícitamente, en todas las tipologías de actividades de ED revisadas: Sensibilización, Formación, Investigación e Incidencia Política.

Se entiende por Sensibilización, el conjunto de actividades a corto plazo que pretenden llamar la atención sobre las causas de la pobreza y las estructuras que las perpetúan; por Formación, el proceso educativo a medio y largo plazo destinado a la comprensión de las desigualdades para promover actitudes de cambio; por Investigación, el análisis de la problemática del desarrollo para generar propuestas e innovaciones en pos del desarrollo humano; y por Incidencia Política, la influencia de los distintos sectores sociales en las decisiones políticas que condicionan la pobreza en el Sur (Ortega, 2008).

Con estas dimensiones como trasfondo, se han desarrollado distintas clasificaciones de actividades de ED, algunas provenientes del ámbito de las ONGD (Pino et al. 2000; Mesa, 2000; Burgos, 2007; Macarro y Burgos, 2009; FAMSI, 2010, BAOBAB-EDUALTER 2010) y otras del ámbito universitario (Freres y Cabo, 2003; Unceta, 2007; Arias y Molina, 2008). Éstas últimas, si bien no hacen referencia exclusiva a actividades de ED, las incluyen como parte de las acciones de cooperación que realizan las universidades.

Para el ámbito universitario, una de las primeras clasificaciones que se desarrollaron fue la de Cristian Freres y Carlos Cabo (2003), que establece un marco general sobre el que situar distintas actividades de cooperación que la Universidad venía realizando. Posteriormente, Koldo Unceta (2007) desarrolla una tipología exhaustiva de dichas acciones, elaborando un listado extenso y haciendo un esfuerzo de conceptualización. Más tarde, Silvia Arias y Estefanía Molina, en 2008, avanzaron sobre esta tipología proponiendo nuevas sub-categorías y actividades, así como una nueva clasificación dentro de las acciones de sensibilización.

En el presente estudio se ha realizado una nueva clasificación a partir de las dos últimas tipologías mencionadas en el párrafo anterior (Unceta, 2007; Arias y Molina, 2008), tomando de ellas sólo las acciones relacionadas con la ED. 
Para ello, se procedió a revisar el título y la descripción de todos los registros de la $\mathrm{AOD}-\mathrm{ED}_{\text {univ }}$, detectando actividades semejantes y generando una primera clasificación inductiva (véase Tabla 2).

Tabla 2

Tipología de Actividades de la AOD-ED en el espacio universitario

\begin{tabular}{|c|c|c|c|}
\hline \multicolumn{2}{|l|}{ Marco general. } & \multicolumn{2}{|l|}{ Proceso inductivo. } \\
\hline \multicolumn{2}{|c|}{ (Unceta, 2007; Arias y Molina, 2008) } & \multicolumn{2}{|c|}{ (Cuando los proyectos en su título o su descripción hacen referencia a ...) } \\
\hline \multirow{5}{*}{$\begin{array}{l}\text { Actividades en } \\
\text { formación de grado } \\
\text { y post-grado (con } \\
\text { reconocimiento } \\
\text { académico expreso) }\end{array}$} & Asignatura & Asignatura & Asignaturas en general. \\
\hline & \multirow[b]{2}{*}{ Postgrado } & Máster & Máster (oficiales y de título propio). \\
\hline & & $\begin{array}{l}\text { Especialista } \\
\text { Universitario }\end{array}$ & $\begin{array}{l}\text { Cursos de especialista, experto universitario en } \\
\text { cooperación, ED, etc. }\end{array}$ \\
\hline & \multirow{2}{*}{ Prácticas } & Prácticas & $\begin{array}{l}\text { Programas de prácticas de fin de carrera, de } \\
\text { cooperación, etc. }\end{array}$ \\
\hline & & Becas & $\begin{array}{l}\text { Becas de formación, de colaboración, de post- } \\
\text { grado, etc. }\end{array}$ \\
\hline $\begin{array}{l}\text { Acciones en } \\
\text { investigación }\end{array}$ & Investigación & Investigación & $\begin{array}{l}\text { Investigaciones (estudios de percepción, } \\
\text { evaluaciones, informes, etc.) }\end{array}$ \\
\hline \multirow{7}{*}{$\begin{array}{l}\text { Actividades en } \\
\text { difusión y } \\
\text { sensibilización }^{23}\end{array}$} & $\begin{array}{l}\text { Convenios de } \\
\text { ONGD con la } \\
\text { AECID* }\end{array}$ & $\begin{array}{l}\text { Convenios de ONGD } \\
\text { con la AECID }\end{array}$ & $\begin{array}{l}\text { Convenios de ONGD con la AECID que incluyen } \\
\text { una gran variedad de actividades, mayoritariamente } \\
\text { de sensibilización }{ }^{24} \text {. }\end{array}$ \\
\hline & \multirow{6}{*}{$\begin{array}{l}\text { Acciones } \\
\text { formativas }\end{array}$} & Cursos monográficos & $\begin{array}{l}\text { Cursos de formación y difusión sin reconocimiento } \\
\text { académico expreso. }\end{array}$ \\
\hline & & Curso On-line & $\begin{array}{l}\text { Curso on-line que no cuentan con reconocimiento } \\
\text { académico expreso. }\end{array}$ \\
\hline & & Conferencias & Conferencias, ciclos de conferencias, charlas, etc. \\
\hline & & Congresos & $\begin{array}{l}\text { Congresos, de educación ambiental, de universidad } \\
\text { y cooperación, etc. }\end{array}$ \\
\hline & & Programas de ED & $\begin{array}{l}\text { Programas de educación, sensibilización, } \\
\text { formación, etc., que incluyen varias actividades y } \\
\text { que no cuentan con reconocimiento académico } \\
\text { expreso. }\end{array}$ \\
\hline & & $\begin{array}{l}\text { Seminarios/Encuentros } \\
\text { /Jornadas }\end{array}$ & $\begin{array}{l}\text { La realización de seminarios, simposios, jornadas, } \\
\text { encuentros y convivencias. }\end{array}$ \\
\hline
\end{tabular}

${ }^{23}$ Entre las actividades de sensibilización se sitúan aquellas que guardan mayor relación con la dimensión de la incidencia política.

${ }^{24}$ Los convenios de ONGD con la AECID han sido considerados como un tipo de actividad debido a su peculiaridad que podía distorsionar los resultados. En primer lugar debido al elevado montante que suponían, casi un $23 \%$ del total de los fondos en tan sólo 8 proyectos. Proyectos con un importe total anual medio de 265.819 euros frente a los 20.595 euros de media del resto de los proyectos de ED analizados. Estos datos se ratificaron con un listado de convenios facilitado por la AECID. A continuación, se les aplicó un factor de corrección para mostrar qué cuantía de ellos había sido destinada realmente al espacio universitario (ver en Metodología), consideramos no obstante conveniente dejarlo en la clasificación, puesto que era difícil encajarlo en una única actividad dada la pluralidad de actividades que un convenio de ONGD recoge. Los convenios de ONGD con la AECID entonces pasaron a suponer un 3,64\% del total de los fondos, como se muestra en la Tabla 3. 
Tabla 2 (continuación)

Tipología de Actividades de la AOD-ED en el espacio universitario

\begin{tabular}{|c|c|c|c|}
\hline \multirow{2}{*}{\multicolumn{2}{|c|}{$\begin{array}{l}\text { Marco general. } \\
\text { (Unceta, 2007; Arias y Molina, 2008) }\end{array}$}} & \multicolumn{2}{|l|}{ Proceso inductivo. } \\
\hline & & \multicolumn{2}{|c|}{ (Cuando los proyectos en su título o su descripción hacen referencia a ...) } \\
\hline \multirow{10}{*}{$\begin{array}{l}\text { Actividades en } \\
\text { difusión y } \\
\text { sensibilización } \\
\text { (continuación) }\end{array}$} & \multirow{4}{*}{$\begin{array}{l}\text { Publicaciones y } \\
\text { centros } \\
\text { documentales }\end{array}$} & $\begin{array}{l}\text { Edición de Libros y } \\
\text { otras Publicaciones }\end{array}$ & $\begin{array}{l}\text { La presentación y edición de libros, la creación y } \\
\text { publicación de otros materiales (cuadernos, CD, } \\
\text { carteles, etc.). }\end{array}$ \\
\hline & & Fondos Documentales & La adquisición de fondos documentales. \\
\hline & & Nuevas Tecnologías & $\begin{array}{l}\text { La creación de redes interuniversitarias, de blogs, } \\
\text { páginas web, etc. }\end{array}$ \\
\hline & & Documentales & La elaboración de documentales. \\
\hline & Voluntariado & Voluntariado & Voluntariado, universitario, internacional, etc. \\
\hline & \begin{tabular}{|l|} 
Convocatoria a \\
proyectos
\end{tabular} & $\begin{array}{l}\text { Convocatoria a } \\
\text { Proyectos }\end{array}$ & Convocatorias para realizar actividades de ED. \\
\hline & \multirow{4}{*}{$\begin{array}{l}\text { Acciones de } \\
\text { sensibilización }\end{array}$} & Campañas & $\begin{array}{l}\text { Campañas de diferentes temáticas y que contienen } \\
\text { diversas actividades. }\end{array}$ \\
\hline & & Exposiciones & La creación y/o muestra de exposiciones. \\
\hline & & Concursos & $\begin{array}{l}\text { Concursos y premios (de fotografía, de ideas, de } \\
\text { carteles, lemas, etc.). }\end{array}$ \\
\hline & & $\begin{array}{l}\text { Ciclos de cine y } \\
\text { Festivales }\end{array}$ & Ciclos de cine, cine-forum y festivales de cine. \\
\hline \multirow[t]{2}{*}{ Otros } & $\begin{array}{l}\text { Estructura } \\
\text { Solidaria }\end{array}$ & Estructura solidaria & $\begin{array}{l}\text { Apoyo al funcionamiento de las estructuras } \\
\text { solidarias (creación y apoyo de cátedras de } \\
\text { cooperación, observatorios, etc. })^{25} \text {. }\end{array}$ \\
\hline & Otros & Otras Actividades & $\begin{array}{l}\text { Otras actividades no incluidas en apartados } \\
\text { anteriores. }\end{array}$ \\
\hline
\end{tabular}

* Esta actividad no estaba considerada en la clasificación original propuesta por los autores.

Fuente: Elaboración propia a partir de datos del Seguimiento PACI consolidado de SGCID (20062010), y de K. Unceta (2007) y S. Arias y E. Molina (2008).

Las tipologías elaboradas desde el ámbito universitario han seguido un proceso de construcción conjunta, de manera que clasificaciones más recientes se han ido asentando sobre tipologías previas. Estas clasificaciones, además, comparten una cierta "perspectiva universitaria", la cual tiende a considerar como formación dentro del ámbito de la Universidad aquella que cuenta con reconocimiento institucional. Por lo tanto, entiende bajo el paraguas de la formación, aquellos cursos, másteres, etc., que cuentan con un reconocimiento académico expreso en créditos o titulación oficial y así aparece recogido en el título o la descripción del proyecto.

${ }^{25}$ Bajo esta clasificación se ha incluido los gastos para la creación y funcionamiento de las "Estructuras Solidarias", que juegan una imprescindible labor de ED en la Universidad. Además de mantener un personal que informa al alumnado y organiza diversas actividades de ED, la sola existencia de una estructura que visibilice, canalice las inquietudes solidarias y haga presente de manera permanente en la vida universitaria actividades relacionadas con la solidaridad, es vital para la ED. Así, la solidaridad va más allá de una actividad puntual en el aula y se incorpora al entramado institucional universitario. 
El presente estudio aporta al proceso de construcción conjunta, una visión de la tipología de actividades de la ED según la AOD, compartiendo además la "perspectiva universitaria", por la cual, aquellas actividades que no tiene reconocimiento universitario expreso como formación, quedarán recogidas bajo el paraguas de "Acciones Formativas" dentro de las "Actividades de difusión y sensibilización". Al hacer esto, también se quiere destacar la relevancia que tiene para los autores que las actividades formativas de ED cuenten con el aval de la institución académica correspondiente.

La tipología mostrada en la Tabla 2 es fruto de la información aportada por los Seguimientos PACI anuales, los cuales presentan una serie de restricciones a la hora de obtener una visión ajustada de la ED realizada en Universidad. Una de ellas es donde situar el límite entre proyecto y actividad. Muchos de los títulos y descripciones de los proyectos de ED son de tipo genérico o inclusivo. Es decir que contienen diversas actividades de ED. Hay proyectos cuyo título y/o descripción hacen referencia a una actividad formativa concreta, por ejemplo Másteres de Cooperación, pero que contienen otras actividades subsidiarias como seminarios e incluso acciones de incidencia ${ }^{26}$, que no han sido expresamente recogidas en su título o descripción. Por lo tanto, la dinámica seguida ha sido identificar la actividad principal a la que el proyecto hacía referencia, dejando categorías genéricas para proyectos que hacían alusión expresa a varias actividades como en los Convenios de ONGD con la AECID, los Programas de ED y las Convocatorias a proyectos.

\subsection{Actividades de Educación para el Desarrollo en la Universidad}

La ED desarrollada en España ha prestado una mayor atención a las acciones que tienen que ver con la dimensión de la sensibilización (Burgos, 2007; Escu-

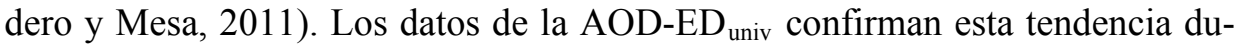
rante el periodo de estudio, de manera que de un total de 818 proyectos, el $81,3 \%$ han sido actividades de difusión y sensibilización, lo que supone un $67,10 \%$ de la AOD-ED univ $_{\text {(véase Tabla } 3 \text { ). }}$

Bajo el paraguas de actividades de sensibilización tienen cabida una serie de acciones que también implican algún tipo de formación, que, no obstante, son de corta duración y frecuentemente carecen de un reconocimiento académico. Estas son las llamadas "acciones formativas" 27 : cursos monográficos, cursos

${ }^{26}$ También resulta difícil dirimir qué actividades son específicas de cada una de las dimensiones, pues ocurre frecuentemente que acciones como las campañas, tienen una componente de sensibilización, pero también una de incidencia. Además, los proyectos que trabajan la incidencia no lo suelen reflejar manifiestamente en sus títulos y descripciones.

${ }^{27}$ Algunas de estas actividades, aunque puedan implicar un reconocimiento de créditos de libre configuración, al no reconocerlo expresamente en su título o su descripción, no han sido introducidas dentro de la formación de grado y post-grado. 
on-line, programas educativos, conferencias, congresos, seminarios, jornadas, etc., que han tenido un peso significativo durante el periodo (véase la Tabla 3).

Tabla 3

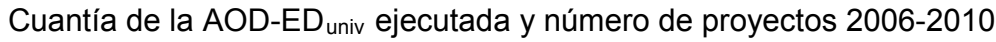

\begin{tabular}{|c|c|c|c|}
\hline Tipología de Actividades & $\begin{array}{c}\mathbf{N}^{\circ} \text { de } \\
\text { Proyectos }\end{array}$ & Cuantía (€) & $\%$ \\
\hline Acciones de formación de grado y post-grado & 90 & 3.665 .249 & $21,89 \%$ \\
\hline Asignatura & 20 & 834.314 & $4,98 \%$ \\
\hline Postgrado & 37 & 2.211 .032 & $13,20 \%$ \\
\hline Prácticas de Cooperación & 33 & 619.902 & $3,70 \%$ \\
\hline Acciones en el campo de la investigación & 17 & 458.793 & $2,74 \%$ \\
\hline Actividades de difusión y sensibilización & 665 & 11.236 .902 & $67,10 \%$ \\
\hline Acciones formativas & 414 & 5.868 .381 & $35,04 \%$ \\
\hline Convenios de ONGD con la AECID & $20(8)^{*}$ & 608.981 & $3,64 \%$ \\
\hline Convocatoria a Proyectos & 7 & 720.355 & $4,30 \%$ \\
\hline Publicaciones y centros documentales & 69 & 873.137 & $5,21 \%$ \\
\hline Voluntariado & 21 & 1.117 .803 & $6,67 \%$ \\
\hline Acciones de sensibilización & 133 & 2.048 .245 & $12,23 \%$ \\
\hline Estructura Solidaria & 46 & 1.386 .609 & $8,28 \%$ \\
\hline Total general & $\mathbf{8 1 8}$ & $\mathbf{1 6 . 7 4 7 . 5 5 2}$ & $\mathbf{1 0 0 , 0 0 \%}$ \\
\hline
\end{tabular}

* Los convenios de ONGD son 8 pero en la tabla aparecen 20 registros, debido a que los convenios son por cuatro años, y cada desembolso anual implica un registro.

Fuente: Seguimiento PACI consolidado de SGCID (2006-2010). Elaboración propia.

Por otro lado, las actividades propias del quehacer diario de la Universidad, la formación reglada de grado y post-grado y la investigación, no han supuesto un porcentaje tan importante. Siendo como son las actividades centrales de la Universidad, sólo han supuesto un $24,62 \%$ de la $A O D-E_{\text {univ }}$ ejecutada durante el quinquenio (véase la Tabla 3).

No obstante, como ya ha sido mencionado, estos datos deben ser tomados con cautela. Sólo recogen los gastos declarados como AOD, y por lo tanto no necesariamente reflejan todas las actividades de formación en ED realizadas en el espacio universitario ${ }^{28}$.

${ }^{28}$ Las Universidades realizan acciones de formación relacionadas con la ED que no son necesariamente declaradas como AOD. El estudio de la cooperación al desarrollo universitaria realizado por K. Unceta (2007) para el periodo 2005-2008, muestra que las acciones de formación de grado y post-grado supusieron un $40,49 \%$ de las acciones de ED realizadas por la Universidad; y las de investigación, un 24,38\%. En su conjunto, supondrían más de la mitad de las acciones realizadas en dicho periodo, y un porcentaje superior a las acciones de difusión y sensibilización. 


\subsection{Actores de la Educación para el Desarrollo en el espacio universitario}

La AOD-ED ${ }_{\text {univ }}$ ha sido ejecutada por diversos actores: ONGD, la propia Universidad (directamente o a través de una estructura solidaria) ${ }^{29}$, por vía directa del resto de las administraciones públicas o a través de otros organismos ${ }^{30}$.

Los actores principales durante el periodo 2006-2010 han sido las ONGD y la Universidad. Entre ambas han ejecutado prácticamente la totalidad (92,92\%) de la cuantía de AOD-ED ${ }_{\text {univ }}$, razón por la cual en los siguientes análisis se van a considerar exclusivamente dichos actores (véase Figura 4).

Figura 4

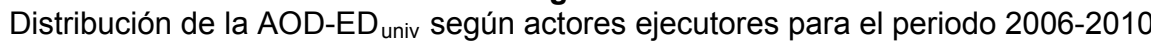

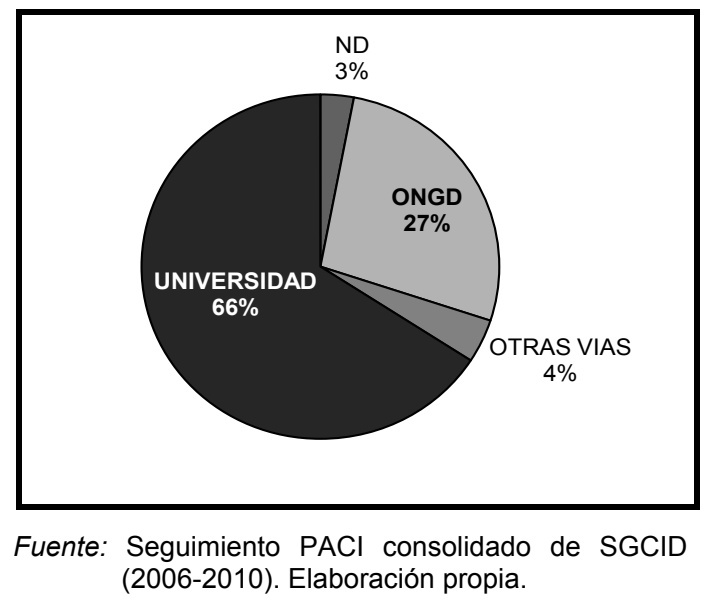

De entre estos dos agentes, la Universidad se ha constituido como el principal actor para el periodo de estudio, ejecutando en el ámbito que le es propio una mayor cuantía (11,02 millones de euros), que equivale a un $65,85 \%$ del monto total de la AOD-ED univ $_{\text {. }}$

Como se sostuvo en la introducción, el nuevo contexto de la cooperación hace que la colaboración entre los actores de la ED en el espacio universitario (Universidad y ONGD) sea todavía más necesaria. El hecho de que ambos agentes tengan el mismo público para sus acciones de ED es una oportunidad

${ }^{29}$ A los proyectos financiados por la propia Universidad pero que en la columna de agente ejecutor figuraba "vía directa" o bien "ND" (no hay datos), se les ha asignado como ejecutor la propia universidad, directamente o a través de su estructura solidaria. En total han sido 260 registros (143 como ND y 117 como "vía directa" u "otras vías".

${ }^{30}$ También se han encontrado 34 proyectos que no tenían ninguna referencia sobre su agente ejecutor. 
para la coordinación, como también lo es, como se mostrará seguidamente, que cada actor se haya "especializado" en diferentes tipos de actividades durante el quinquenio.

La Tabla 4 sintetiza el porcentaje de AOD que cada uno de estos dos actores, Universidad y ONGD, ha ejecutado en el espacio universitario en cada una de las actividades descritas anteriormente.

Tabla 4

AOD-ED ${ }_{\text {univ }}$ ejecutada según actor para el periodo 2006-2010

\begin{tabular}{|l|r|r|r|r|}
\hline \multirow{2}{*}{ TIPOLOGÍA DE ACTIVIDADES EJECUTADAS POR } & \multicolumn{1}{|c|}{ UNIVERSIDAD } & \multicolumn{2}{|c|}{ ONGD } \\
\cline { 2 - 5 } & \multicolumn{1}{|c|}{$€$} & \multicolumn{1}{c|}{$\%$} & $\boldsymbol{1}$ & $\%$ \\
\hline $\begin{array}{l}\text { Actividades en el campo de la formación de grado y } \\
\text { post-grado }\end{array}$ & 3.576 .284 & $32,38 \%$ & 50.900 & $1,12 \%$ \\
\hline Acciones en el campo de la investigación & 220.545 & $2,00 \%$ & 201.681 & $4,45 \%$ \\
\hline Actividades de difusión y sensibilización & 5.964 .170 & $54,00 \%$ & 4.255 .051 & $93,85 \%$ \\
\hline Acciones formativas & 3.434 .266 & $31,09 \%$ & 1.923 .600 & $42,43 \%$ \\
\hline Acciones de sensibilización & 463.303 & $4,19 \%$ & 1.414 .467 & $31,19 \%$ \\
\hline Otras actividades & 2.066 .601 & $18,71 \%$ & 916.984 & $20,23 \%$ \\
\hline Estructura solidaria & 1.283 .939 & $11,62 \%$ & 26.138 & $0,58 \%$ \\
\hline Total general & $\mathbf{1 1 . 0 4 4 . 9 3 8}$ & $\mathbf{1 0 0 , 0 0 \%}$ & $\mathbf{4 . 5 3 3 . 5 1 3}$ & $\mathbf{1 0 0 , 0 0 \%}$ \\
\hline
\end{tabular}

Fuente: Seguimiento PACI consolidado de SGCID (2006-2010). Elaboración propia.

Como puede observarse, el $93,85 \%$ de la AOD-ED univ $_{\text {ejecutada por las }}$ ONGD ha sido para la realización de actividades de difusión y sensibilización. Además, en términos absolutos, esta inclinación de las ONGD hacia este tipo de actividades ha seguido una tendencia creciente a lo largo del quinquenio, como se pone de manifiesto en la Figura 5.

Por el contrario, la Universidad ha mostrado una mayor tendencia a realizar actividades que guardan relación con la formación curricular de grado y post-

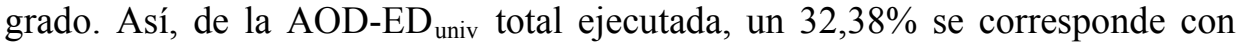
este tipo de actividades. Tendencia que, además, ha sido creciente a lo largo del periodo, especialmente durante los años 2008 y 2010, cuando este tipo de actividades experimentaron un crecimiento exponencial del $357 \%$, mientras que las acciones de difusión y sensibilización se redujeron en un $27,03 \%$ a partir de año 2007 (véase la Figura 6). 
Figura 5

Evolución de la AOD-ED univ ejecutada por las ONGD según actividades durante el periodo $2006-2010^{31}$

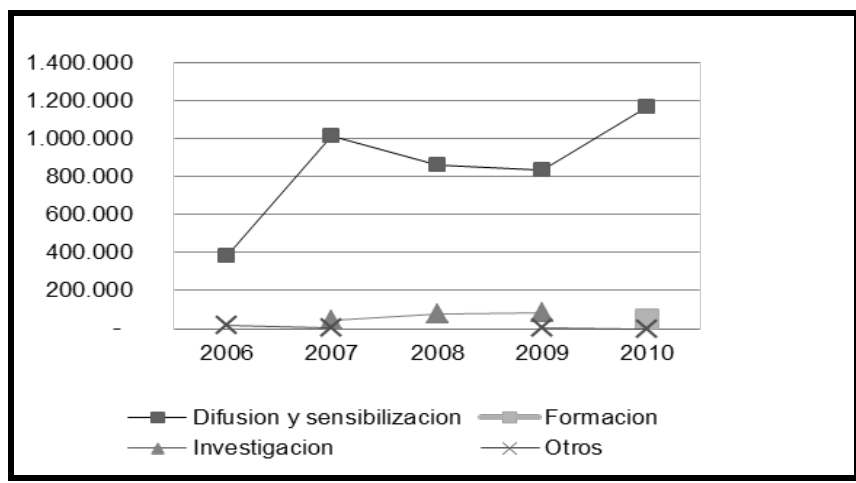

Fuente: Seguimiento PACI consolidado de SGCID (2006-2010). Elaboración propia.

Figura 6

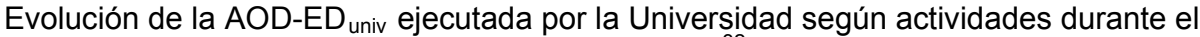
periodo $2006-2010^{32}$

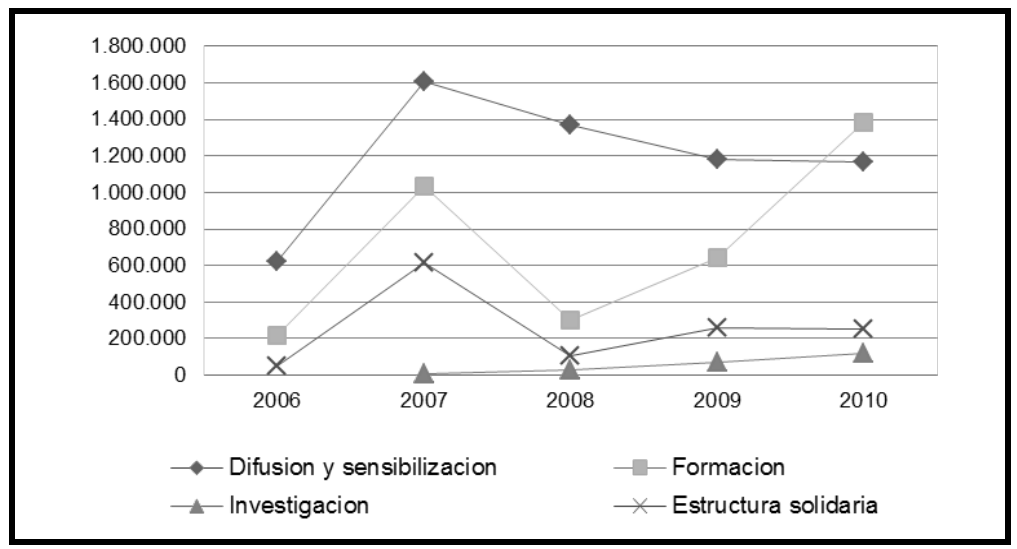

Fuente: Seguimiento PACI consolidado de SGCID (2006-2010). Elaboración propia.

${ }^{31}$ En esta figura se muestran los gastos correspondientes a actividades no factibles de englobar en las clasificaciones genéricas en "otros". Entre estos gastos computados como "otros", no existen aquellos destinados a la "Estructura solidaria", pues las ONGD no suelen dedicar recursos para tal fin.

${ }^{32}$ En esta figura se muestran los gastos correspondientes a actividades no factibles de englobar en las clasificaciones genéricas, como gastos destinados a la "Estructura solidaria", pues las actividades de la Universidad cuando no se engloban en las clasificaciones restantes es porque van destinadas a este fin. 
En cuanto a la investigación, en la Tabla 4 se observa como la cuantía de AOD-ED $D_{\text {univ }}$ destinada a tal fin por ambos actores durante el periodo ha sido similar y a la baja, aunque porcentualmente superior para las ONGD. Estos resultados podrían llevar a concluir que la Universidad ha tenido un escaso papel en la investigación en el área del desarrollo, no obstante respecto a este punto es necesario actuar con cautela, ya que la Universidad genera investigación en torno al desarrollo, la cooperación y la ED que no depende de fondos contabilizados como AOD, sino de fuentes de financiación propias de la actividad investigadora y que, por diversos motivos, aún pudiendo contabilizarse como AOD no son contabilizados como tal.

\subsection{ONGD y Universidad: en vías de la especialización}

El análisis de los datos parece sugerir que, de facto, se está produciendo ya una cierta especialización en la tipología de actividades de ED que ejecutan en el espacio universitario las ONGD y las universidades.

Figura 7

AOD-ED univ según actividad y tipo de actor en el periodo 2006-2010

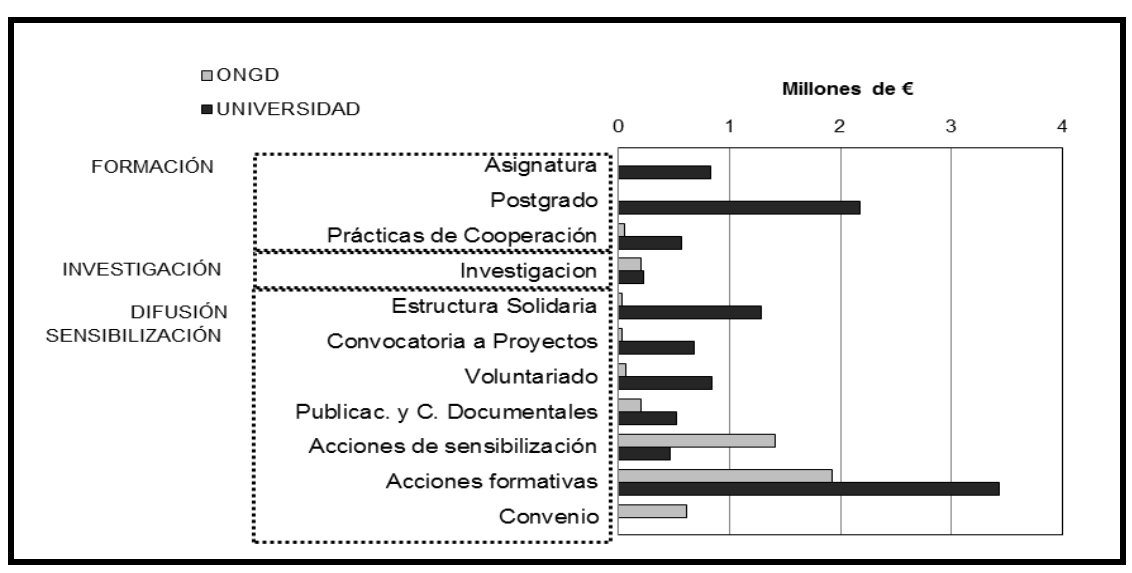

Fuente: Seguimiento PACI consolidado de SGCID (2006-2010). Elaboración propia.

En la Figura 7 se representa la AOD-ED ${ }_{\text {univ, }}$ distinguiendo en gris claro aquélla que ha sido ejecutada por ONGD para el periodo de estudio, y en gris oscuro la ejecutada por la Universidad. Dicha representación permite observar

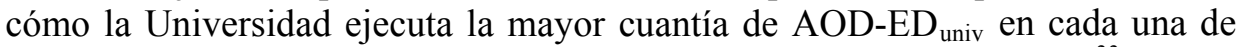
las tipologías de actividades, excepto en las acciones de sensibilización ${ }^{33}$.

\footnotetext{
${ }^{33}$ Igualmente ocurre con los convenios de ONGD con la AECID, pero la razón es distinta, ya que esta herramienta de financiación es de acceso exclusivo para las ONGD.
} 
Profundizando en el análisis, se observa que existen actividades exclusivas o casi exclusivas de la Universidad, como la formación reglada, el apoyo a las estructuras solidarias, las convocatorias a proyectos y el voluntariado universitario. Mientras que, en aquellas que a día de hoy son compartidas en mayor o menor medida con las ONGD, se puede ver claramente la primacía de uno u otro agente; a saber, las ONGD en las actividades de sensibilización, y la Universidad en las demás.

Siendo esto así, se puede afirmar que ya está produciéndose una cierta especialización de cada uno de estos dos actores. Esta realidad, resumida en la Figura 8 (que representa de manera esquemática los campos de acción propios y compartidos según el tipo de agente), supone una oportunidad para el establecimiento de una estrategia de acción compartida entre estos dos actores, especializándose en aquellas actividades que le son propias, y profundizando en su coordinación en aquellas actividades para las que cabe esperar una colaboración más efectiva.

Figura 8

Esquema de las actividades ejecutadas por ONGD y Universidad

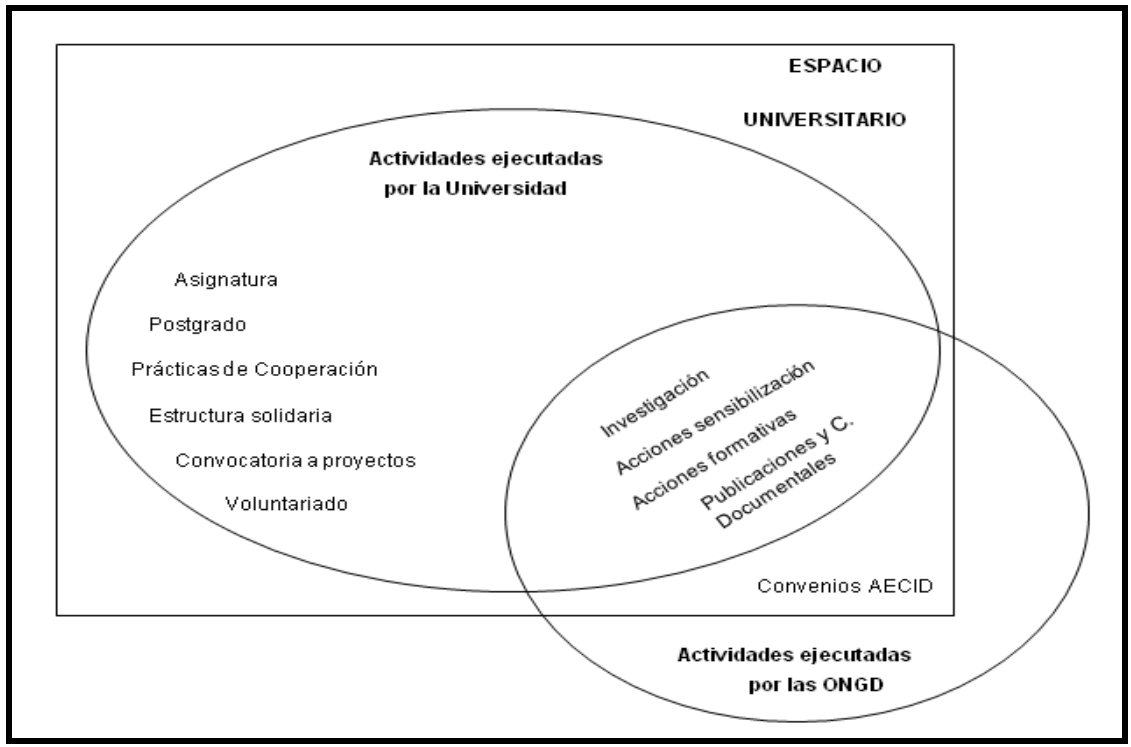

Fuente: Elaboración propia.

\section{CONCLUSIONES}

La Educación para el Desarrollo como parte del sistema de cooperación internacional juega un importante papel en el espacio universitario. En la última 
década la ED ha ido ganando reconocimiento teórico dentro del sistema de cooperación española, creciendo en términos económicos absolutos durante el periodo 2006-2010. No obstante, el crecimiento relativo de la AOD-ED respecto al total de la AOD ha sido moderado. De tal manera, consideramos que la AOD-ED dentro del sistema de cooperación ha tenido un sobrio incremento en comparación con el crecimiento de la AOD, y estas cifras difícilmente permitirán alcanzar al final del periodo el mínimo acordado en el III Plan Director de la Cooperación Española de 2009 a 2012.

La AOD ejecutada como ED en el espacio universitario durante el periodo de estudio ha supuesto un porcentaje menor al estimado por la literatura existente. Consideramos que su evolución durante el quinquenio ha estado fuertemente condicionada por el propio proceso de contabilización y la reciente incorporación de las universidades al mismo. Una de las recomendaciones que extraemos de este trabajo, es que consideramos necesario que la Universidad establezca mecanismos que permitan contabilizar mejor los recursos que destina a AOD que actualmente no son contabilizados, como creemos ocurre en investigación pero también en docencia y extensión universitaria.

Los principales agentes que han ejecutado AOD-ED en el espacio universitario durante el quinquenio han sido la Universidad, en primer término, y las ONGD, en segundo.

Estos dos agentes han desarrollado a lo largo del periodo 2006-2010 una serie de actividades de manera preeminente y diferenciada. Así, mientras la Universidad ha jugado un papel central en acciones de ED relacionadas con la formación académica universitaria (formación de grado y postgrado con reconocimiento académico), las ONGD se han distinguido por acciones puntuales más relacionadas con la difusión y la sensibilización. No obstante, otras acciones, como las formativas puntuales (cursos, seminarios, jornadas, etc.), han sido ejecutadas por ambos actores, configurándose como un espacio de encuentro de las acciones educativas de ONGD y Universidad.

La reducción presupuestaria de la cooperación para el desarrollo conlleva una llamada de atención sobre la necesidad de la eficacia y la eficiencia de la ayuda. Hacia esa dirección se ha querido apuntar con el presente artículo, destacando la oportunidad de coordinación que existe entre los dos agentes más relevantes de la ED en la universidad, en virtud de la especialización que ya se está produciendo en las actividades que realizan.

La Universidad ha venido jugando un importante papel en el campo de la formación de grado y postgrado, y tiene extensa experiencia, más allá de la mostrada en el presente artículo. Las ONGD han venido desarrollando actividades de difusión y sensibilización. Esta especialización por ámbitos de actividad, debe ser aprovechada en base a la experiencia y las facilidades coyunturales de cada uno de los actores. Se deben pues favorecer espacios de diálogo e inter- 
cambio (seminarios, jornadas, redes, etc.) entre estos actores en torno a la ED, de los que se puedan obtener criterios de buenas prácticas de coordinación, protocolos, agendas comunes, etc.

Todas las etapas (sensibilización, formación, investigación e incidencia política) de la Educación para el Desarrollo constituyen piezas esenciales del proceso, pues son los peldaños de un sistema educativo integral que trabaja sobre aspectos emocionales, cognitivos, y prácticos de la persona. Por lo tanto, el hecho de que exista una cierta especialización por actividades entre las ONGD y la Universidad podría favorecer una adecuada coordinación que garantice todas las etapas de este proceso. Más aún, abre la oportunidad para el desarrollo de una estrategia conjunta que aproveche la experiencia acumulada de cada uno de estos dos actores.

\section{REFERENCIAS BIBLIOGRÁFICAS}

ALONSO, J.A.; AGUIRRE, P. y CASTILLO, A. (2012): "La cooperación al desarrollo y la infancia. Apuntes estratégicos para el caso de España", en ICEI Workingpapers. http://eprints.ucm.es/14650/ (Último acceso: 14/07/2012)

ARIAS, S. y SIMÓN, A. (2004): Las Estructuras Solidarias de las Universidades Españolas. Organización y Funcionamiento, Madrid: Universidad Autónoma de Madrid y Fundación Telefónica.

ARIAS, S. y MOLINA, E. (2008): Universidad y Cooperación al Desarrollo. La experiencia de las universidades de la ciudad de Madrid, Madrid: CATARATA.

ASENJO, C.; JERCH, M. y VILLANUEVA, M. (2007). Seguimiento del PACI 2006. Aumentar la calidad y la cantidad de nuestra ayuda mediante una mayor coordinación entre los agentes de la cooperación española. Madrid: SECI-DGPOLDE-MAEC.

ASENJO, C.; VILLANUEVA, M.; FUERTES, S., y SEOANE, J. (2008): Seguimiento del PACI 2007. Mejorar la eficacia de la ayuda a través de la armonización, incrementando la asignación para la cobertura de necesidades sociales, Madrid: SECI-DGPOLDE-MAEC.

BAOBAB-EDUALTER (2010): Caracterització $i$ anàlisis de l'Educació per al Desenvolupament a Catalunya, Barcelona: Agencia Catalana de Cooperació al Desenvolupament.

BASELGA, P; FERRERO, G. y BONI, A. (coords.) (2004): La educación para el desarrollo en el ámbito formal, espacio común de la cooperación y la educación. Propuestas para una estrategia de acción integrada, Valencia: Editorial de la UPV. 
BONI, A. (2005): La educación para el desarrollo en la enseñanza universitaria como una estrategia de la cooperación orientada al desarrollo humano, Valencia: Universitat de Valencia - Tesis Doctoral.

BONI, A. (2006): "La Educación Universitaria ¿Hacia el Desarrollo Humano?", en Boni, A. y Pérez-Forguet, A. (coord.): Construir la ciudadanía global desde la universidad, pp. 91-107, Barcelona: Intermon Oxfam ediciones.

BURGOS, M. (2007): Estudio sobre la educación para el desarrollo en Andalucía. Fase l: Administraciones Públicas (2004-2005), Sevilla: Coordinadora Andaluza de ONGD.

CENTRO NORTE - SUR del Consejo de Europa (2002): Declaración de Maastricht 2005-2014 sobre Educación Global en Europa [en línea], disponible en: http://www.coe.int/t/dg4/nscentre/GE/GE-Guidelines/GEgs-app1.pdf [Último acceso: 29/05/2012].

CONSEJO DE LA UNIÓN EUROPEA (2001): Council Resolution on development education and raising european public awareness of development cooperation [en línea], disponible en: http://trade.ec.europa.eu/doclib/html/ 122286.htm [Último acceso: 28/05/2012]

ESCUDERO, J. y MESA, M. (2011): Diagnóstico de la Educación para el Desarrollo en España, Madrid: Centro de Investigación para la Paz.

FAMSI (2010). Análisis de datos del sondeo sobre actuaciones e intereses en Educación para el Desarrollo por parte de las Entidades Locales, Córdoba: FAMSI y Ayuntamiento de Córdoba.

FRERES, C. y CABO, C. (2003): Las Universidades de la Comunidad de Madrid y la Cooperación al Desarrollo, Madrid: Comunidad de Madrid.

GUTIÉRREZ, B.; ARAQUE, R.; MONTERO, M.J. y ORTEGA, M.L. (2009): "Factores de influencia en la captación de recursos privados en las ONGD españolas", en Estudios de Economía Aplicada, vol. 27, núm. 3, diciembre, 2009, pp. 1-25.

MACARRO, R.M. y BURGOS, M. (2009): Estudio sobre la educación para el desarrollo en Andalucía. Fase II: las organizaciones de la coordinadora andaluza de ONGD (2006-2008), Sevilla: Coordinadora Andaluza de ONGD.

MAEC (2005): ORDEN AEC/1303/2005, de 27 de abril, por la que se regulan las bases para la concesión de subvenciones a organizaciones no gubernamentales de desarrollo, para la realización de intervenciones en materia de cooperación internacional para el desarrollo, Madrid: BOE núm. 113, pp. 16139- 16145.

MAEC (2009): III Plan Director de la Cooperación Española 2009-2012, Madrid: SECI-DGPOLDE.

MAEC (2011): Seguimiento del PACI 2010, Madrid: SECI-DGPOLDE-MAEC.

MESA, M. (2000): La educación para el desarrollo en la Comunidad de Madrid. Tendencias y estrategias para el siglo XXI, Madrid: Dirección General de Cooperación y Voluntariado de la Comunidad de Madrid. 
OCUD (2011): Consenso sobre el reporte de la AOD de las universidades: Vigilancia en la calidad de datos y consenso de criterios para la encuesta del PACl de las universidades http://www.ocud.es/sites/default/files/Consenso \%20Datos\%20PACl_Definitivo.pdf [Último acceso: 14/07/2012]

OECD (2011): Purpose Codes: sector classification, 2011. http://www.oecd.org/ document/18/0,3746,en_2649_34447_1914325_1_1_1_1,00.html. [Ultimo acceso: $11 / 05 / 2012]$

OECD (2012): DAC Glossary of Key Terms and Concepts. 2012. http://www.oecd.org/document/32/0,3343,en_2649_33721_42632800_1_1_ 1_1,00.html [Último acceso: 14/05/2012]

PULIDO, A. (2007): "Conversaciones con Emilio Fontela sobre el futuro de la Universidad". en Estudios de Economía Aplicada, vol. 25, núm. 3, diciembre, 2007, pp. 591-599.

ORTEGA, M.L. (2008): Estrategia de Educación para el Desarrollo de la Cooperación Española, Madrid: SECI-DGPOLDE.

PERIÓDICO ABC (2012): Menos dinero, menos países y menos acuerdos bilaterales. Así será la Ayuda Oficial al Desarrollo, 18/06/2012. http://www.abc.es/20120616/espana/abci-cooperacion-internacional-reparto201206151901.html [Último acceso: 21/06/2012].

PINO, E.; DE LA FUENTE, C.; FERRÁNDIZ, J.L. y GAGO, A. (2000): Una mirada hacia el futuro. Panorama actual y desafíos de la Educación para el Desarrollo en las ONGD de la Coordinadora, Madrid: CONGDE.

UNCETA, K. (2004): "La universidad y la cooperación al desarrollo: hacia un marco de colaboración con las ONGD", en Plataforma 2015 y más (eds): La palabra empeñada, pp. 185-198, Madrid: La Catarata.

UNCETA, K. (2007): La cooperación al desarrollo en las universidades españolas, Madrid: Agencia Española de Cooperación Internacional. 